\title{
Alonso Gurmendi Dunkelberg Conflicto armado en el Perú: la época del terrorismo bajo el derecho internacional
}

Lima, 2019. Universidad del Pacífico. Primera edición. 178 págs.

Este libro, como dice su autor1, «convencido de poder persuadir a mis compatriotas no solo de lo correcto de análisis legal, sino de la conveniencia de respetar y aplicar el derecho internacional» (p. 12), ofrece una visión jurídica de la época del terrorismo en el Perú. Desde la quema de padrones y actas electoras en Chuschi hasta la captura del último alto mando de Sendero Luminoso, "Artemio", utilizando la perspectiva del derecho internacional humanitario, el libro analiza los hechos y el debate de la lucha contrasub-

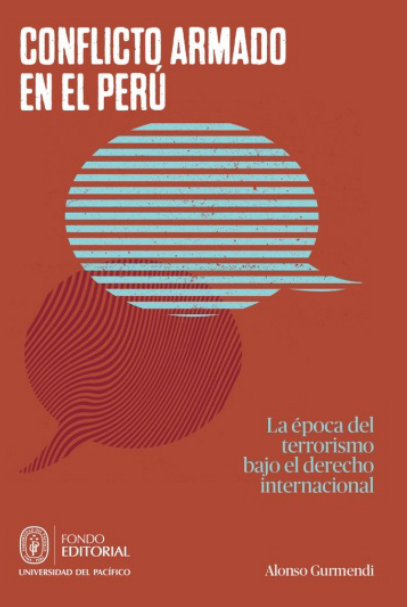

correcta interpretación de lo que sucedía en el Perú[,] tomó más tiempo del que debería»; no fue sino hasta finales de la década de los años ochenta, con los trabajos de Carlos Iván Degregori y Gustavo Gorriti, «que poco a poco la cara real de Sendero como organización político-militar fundamentalista -y no campesina- empieza a aflorar» (p. 20).2 Luego aborda el origen e ideología senderista, modelado a partir de la interpretación de la ideas marxistas, leninistas, maoístas y las del "pensamiento Gonzalo", como una de las versiva y concluye que sí existió un conflicto armado en el Perú.

El capítulo I, «La época del terrorismo en el Perú», relata lo sucedido «desde una perspectiva poco aplicada en el debate público (...) y (...) analiza dicho periodo histórica y legalmente desde los hechos que acontecieron" (p. 16). Comienza con el recuerdo de Chuschi, hecho con el que «los terroristas de Sendero Luminoso se hicieron presentes en el Perú de inicios de los años ochenta» y produjeron grandes incertidumbres sobre «las causas que motivaban su subversión» (p. 17), tanto a nivel académico como político y entre los expertos en materia de insurgencias. La carencia de estudios formales sobre los inicios del fenómeno de la violencia terrorista no ofrecía «la

Alonso Gurmendi es abogado por la Universidad de Lima y magíster en Estudios Internacionales con mención en Derechos Humanos por la Universidad de Georgetown. Cuenta con estudios avanzados en Derecho Internacional Humanitario por la Academia de Ginebra y el Comité Internacional de la Cruz Roja. Actualmente es profesor auxiliar de la Facultad de Derecho en la Universidad del Pacífico. vertientes del comunismo chino que llega al Perú en 1964, "con una ideología hiperviolentista, convencido de la necesidad de la guerra popular y la militarización de la sociedad» (p. 21), que lo llevaría «a la conquista del poder gracias al apoyo popular» (p. 24). El capítulo finaliza con el recuento y análisis de la violencia terrorista desde «la estrategia contrainsurgencia peruana tal cual se desarrolló», comparándola con la doctrina de contrainsurgencia internacional imperante "con el fin de determinar su eficacia» (p. 28).

En el capítulo II, «El derecho internacional de los conflictos armados», se explica el «ropaje jurídico» que regula el derecho al conflicto armado, puesto que si bien la violencia es una «regla ineludible de Ideología y violencia política en Sendero Luminoso de Carlos Iván Degregori, ensayo de 29 páginas publicado por El Zorro de Abajo Ediciones en 1989; y Sendero. Historia de la guerra milenaria en el Perú de Gustavo Gorriti, publicado como primer volumen de una colección de tres por la Editorial Apoyo en 1990.
2 Los trabajos sobre senderismo referidos son Qué difícil es ser Dios. 
la guerra y el conflicto[,] existen normas que buscan rechazar la violencia innecesaria» (p. 54). El derecho internacional humanitario tiene una regulación legal y práctica en los conflictos armados internacionales (entre Estados) y los no internacionales (dentro del Estado); sin embargo, en "los vacíos dejados por el derecho de los conflictos armados, sobre todo en casos de conflicto no internacionales[,] el derecho interno del país en conflicto tendría un rol que cumplir» (p. 70). Los derechos humanos suplieron esos vacíos por su carácter de aplicación continua aún en tiempo de conflicto, dándole a ambos derechos «una especie de retroalimentación» (p. 78). Así, para precisar el concepto de los conflictos armados no internacionales, en 1977 fue aprobado el Segundo Protocolo Adicional a las Convenciones de Ginebra que «es el que se relaciona de forma más directa con el caso peruano» (p. 78).

El capítulo III, «La clasificación legal de la época del terrorismo", brinda el sustento legal ante "un debate mal planteado, mal dirigido y mal explicado" (p. 81) sobre la existencia de un conflicto armado durante la época del terrorismo en el Perú. Para el autor, el Estado peruano sí estaba en condiciones de "realmente saber (...) que se estaba enfrentando a un conflicto armado y no a un disturbio interno" (p. 82); sin embargo, "nunca evaluó, entonces, la naturaleza legal de su lucha contrasubversiva. [Tal] decisión de no aplicar normas internacionales (...) fue consciente y política, con el fin de evitar otorgar cualquier reconocimiento internacional a Sendero Luminoso" (p. 91). Por lo que, frente a un grupo armado organizado y un escenario de violencia armada prolongada e intensa, "en el Perú hubo, sin lugar a dudas, un conflicto armado no internacional” (p. 107).

Con el capítulo IV, "Aplicación del derecho internacional humanitario en el Perú", se ofrecen los argumentos para superar el «sinsentido jurídico y lógico» (p. 112) de la elucubración anticonflicto y así determinar strictu sensu el inicio y fin del conflicto armado. "Sendero Luminoso no pud[o] empezar una guerra hasta que el Perú le responda bélicamente"; por ende, aplicando la perspectiva del DIH, el conflicto empezó cuando las Fuerzas Armadas entran a Ayacucho en 1982, "asumiendo una lógica plenamente militar" (p. 131). El fin "no llegó por un acuerdo, sino cuando las hostilidades y/o la organización de Sendero disminuyeron" (p. 132). Ello ocurrió en 1996 cuando la acción bélica senderista descendió "a un nivel suficiente como para concluir que no se reiniciarían con la misma intensidad de antes" (p. 134), con lo que se pueda hablar "con seguridad de una situación de "paz» por lo menos desde 1997" (p. 135). Respecto al Movimiento Revolucionario Túpac Amaru (MRTA), a pesar de ser "un actor hostil en el conflicto armado" (p. 140), sus acciones quedan "fuera del ámbito de aplicación del derecho internacional humanitario en todos los escenarios" (p. 141). A pesar de ello, "la determinación de conflicto armado no vino desde el sistema jurídico, sino desde la Comisión de la Verdad" (p. 143). Y ahí radica el problema, la Comisión al ser "la primera en efectuar esta determinación, nuestros (...) operadores jurídicos [...] no llegan a realizar un análisis jurídico propio (...) y se limitan solamente a citar los hallazgos de la CVR, y nada más" (p. 144-145).

"Cerrando el círculo», penúltimo capítulo, evidencia la contradicción de fondo en la que actualmente caen nuestras Fuerzas Armadas en la aplicación del DIH en la zona de conflicto denominada Vraem. Si bien dicha zona es azotada por remanente de Sendero, su accionar no lograr alcanzar el rango de violencia armada vivida entre 1983 y 1997; por lo que, si las Fuerzas Armadas ven hoy el rol del DIH "como una herramienta, (...) que rehusó aplicar hace ya casi cuarenta años" (p. 152), entonces la época del terrorismo debería ser reconocido como conflicto armado. Finaliza el libro con el brevísimo capítulo "Conclusiones», que es una invitación del autor, ante la persistente resistencia de dos bandos - una derecha conservadora y una izquierda progresista- de "cambiar una realidad legal ya establecida" (p. 153), para dejar de ver la época del terrorismo en el Perú "como un punto de inflexión de que divide a nuestra sociedad [pues] sería simplemente una lástima que veamos nuestra historia reciente reducida a una pelea de rótulos capaz de empańar la memoria de aquellas personas e historias que realmente debemos honrar y recordar" (p. 154).

Renzo Palacios Medina Universidad Nacional Mayor de San Marcos renzopame@gmail.com 